\title{
Aa. Vv., «Le Courrier balzacien», nouvelle série, n. 100
}

\section{Marco Stupazzoni}

\section{(2) OpenEdition}

\section{Journals}

\section{Edizione digitale}

URL: http://journals.openedition.org/studifrancesi/8972

DOI: 10.4000/studifrancesi.8972

ISSN: 2421-5856

\section{Editore}

Rosenberg \& Sellier

\section{Edizione cartacea}

Data di pubblicazione: 1 octobre 2008

Paginazione: 473

ISSN: 0039-2944

\section{Notizia bibliografica digitale}

Marco Stupazzoni, «Aa. VV., «Le Courrier balzacien», nouvelle série, n. 100», Studi Francesi [Online], 155 (LII | II) | 2008, online dal 30 novembre 2015, consultato il 12 janvier 2021. URL: http:// journals.openedition.org/studifrancesi/8972 ; DOl: https://doi.org/10.4000/studifrancesi.8972

Questo documento è stato generato automaticamente il 12 janvier 2021.

\section{(c) (i) $\odot$}

Studi Francesi è distribuita con Licenza Creative Commons Attribuzione - Non commerciale - Non opere derivate 4.0 Internazionale. 


\title{
Aa. Vv., «Le Courrier balzacien», nouvelle série, n. 100
}

\author{
Marco Stupazzoni
}

\section{NOTIZIA}

«Le Courrier balzacien», nouvelle série, n. 100, double, 2005 (3-4), pp. 115.

1 Di indubbio interesse è il numero monografico del «Courrier balzacien» su La Vieille Fille e Le Cabinet des Antiques (Les Rivalités) curato con esemplare competenza critica e dovizia metodologica da Stéphane VACHON: "Les Rivalités". Analyses et documents.

Pubblicati nel breve arco di tempo che va dal febbraio 1837 al marzo 1839, La Vieille Fille «il primo "roman-feuilleton" della letteratura francese» e Le Cabinet des Antiques compongono il ciclo delle Rivalités nelle Scènes de la vie de province. Queste due opere si mostrano, da un punto di vista genetico-strutturale e tematico, strettamente legate tra loro; ma risultano esserlo anche sotto la prospettiva simbolica «car, à bien des égards, elles professent la même leçon» (p. 21). Concepiti alcuni anni prima in un contesto tutt'altro che favorevole di «désarroi» sentimentale, professionale e finanziario, i due romanzi si fondano su una continuità spazio-temporale e di azione narrativa che fanno risaltare all'attenzione dei lettori «l'affrontement des intérêts contradictoires, l'exacerbation des volontés et les convulsions des individualismes, un monde dans lequel les passions vont toutes à leur assouvissement, au besoin par le calcul, la manipulation, le mensonge» (pp.33-34). Particolarmente curata e ricca di preziose e puntuali notazioni è la sezione dedicata alla genesi dei due romanzi: l'autore fornisce opportunamente «le relevé des passages sur lesquels s'arrête la composition typographique de chaque épreuve de chaque chapitre» (p. 57) che consente di valutare (anche visivamente) in tutta la sua straordinaria complessità e articolazione quel "jeu des épreuves" che "porte un nombre considérable (souvent quasi incalculable) de retouches, d'interventions, d'enrichissements, d'ajonctions, d'amplifications» (p. 46). 
3 Non meno interessante per comprendere appieno la storia e l'evoluzione della progettualità letteraria balzachiana è la densa sezione comprendente $\mathrm{i}$ «documents» relativi al Cabinet des Antiques di cui l'autore offre un rigoroso esame critico: la «Dédicace au baron Hammer-Purgstall», dove per la prima volta Balzac accenna in modo esplicito al disegno della grande opera in formazione; la lettera a Hippolyte Castille del febbraio 1839 e la Préface. L'ultima sezione è dedicata alla «Fortune des Rivalités»: réception de La Vieille Fille; campagne du «Charivari» (automne 1838); une lectrice: Louise Abber à Honoré de Balzac; la lectrice: Mme Hanska; réception du Cabinet des Antiques; article d'Émile Zola sur Le Cabinet des Antiques (31 octobre 1869).

4 Il fascicolo è ulteriormente arricchito dal dettagliato repertorio bibliografico delle edizioni francesi e delle "préfaçons" belghe relative ai due romanzi pubblicate nella prima metà del XIX secolo («Les publications des Rivalité», pp. 108-113). 